\title{
Animal abuse and family violence: Reflections from workshopping with veterinary students
}

Michael Dale and Polly Yeung, School of Social Work, Massey University, Aotearoa New Zealand

\section{Introduction}

The notion of social work teaching in the veterinary science programme may seem novel for our profession. However, the philosophy underlying the context of animal and human welfare in One Health is the result of the collaborative effort of multiple disciplines and professions to attain optimal health for people, animals and the environment. One Health emphasises some of the key domains such as creating an enabling environment and advocating change and communication amongst healthcare professionals (Courtenay et al., 2014). Even when interprofessional education (IPE) and One Health competencies are evident in courses, Courtenay and colleagues (2014) noted that they are mostly at clinical level. In recent years, there has been a call for more collaboration between human and veterinary medicine to learn and practise One Health competencies, and "links" between the abuse of children, vulnerable adults and animals have been identified as a key area for exploration (Arkow, 2015a; Jordan \& Lem, 2014). In 2015, the second author and the Head of School of Social Work at Massey University had the opportunity to skype with Dr Elizabeth Strand, the Founding Director of Veterinary Social Work (VSW) (Strand et al., 2012), from University of Tennessee-Knoxville to discuss setting up VSW and also to seek advice on challenges and strategies on engaging and collaborating with the veterinary school. Dr Strand shared her experiences and encouraged us to contact the Head of the Veterinary School at our university to start a conversation. Our Head of School approached the then Head of School of Veterinary Science and within days a meeting was organised. We went into the meeting expecting a first level of exploration with the Head of School to see if he was interested but were surprised when we were joined by another senior lecturer (SG) who had been re-designing the course content of professional practice for veterinarian students. He was very keen of our idea on working with him to develop a module on teaching his students about the link between animal abuse and family violence. It seemed the Veterinary School had been identifying gaps in their curriculum for some time in relation to health and wellbeing, communication skills and conflict resolution, but they had only accessed support from student health services at the university. He also acknowledged the increasing attention in research literature about the link between human and animal violence as a pivotal area that could be integrated within the Veterinary Science Professional Practice curriculum, but did not realise that social work could play a role in supporting their curriculum and knowledge building. The meeting was a success, and within a year, we started our contribution by running the first two-hour workshop with first-year veterinary students discussing animal abuse and family violence, a workshop which then became a regular feature of the veterinary programme between 2016 and 2018. The purpose of this paper is to provide a description of what was included in the educational contexts, reflections from veterinary students' engagement and future needs to connect between human service and animal service professionals to address the link.
AOTEAROA NEW ZEALAND SOCIAL WORK 33(1), 99-107.

CORRESPONDENCE TO Polly Yeung P.Yeung@massey.ac.nz 
The link between animal abuse and family violence

A growing body of research documents a relationship between animal abuse and child abuse, and domestic violence has been the focus of much international research in recent years (Arkow, 2015b; Ascione et al., 1997; Faver \& Strand, 2003; Newberry, 2017; Volant et al., 2008). Both international and national studies have identified that animals are commonly harmed or killed as a form of family violence and a significant number of women and their children remain in abusive relationships due to concerns for the safety of their pets / animals (Bright et al., 2018; Haden et al., 2018; Roguksi, 2012; Williams et al., 2008). Recognition of this link between animal abuse and family violence has led to a call for greater awareness, and for more interprofessional training, education and cross-referral between human and animal welfare professionals (Holcombe et al., 2016; Newland et al., 2019; Randour et al., 2019; Strand et al., 2012; Williams et al., 2008). Despite the prolific research correlating interpersonal violence, family violence, and child and adult animal cruelty mentioned, challenges for cross-sector reporting are still hindered by the separation of animal and human welfare when it comes to intervention (Long et al., 2007). In recent times, a One Welfare approach has also been established to complement the One Health approach, which focuses on the interconnections between animal welfare, human wellbeing and the environment, in order to improve ways of working in a more integrated approach to achieve better animal welfare and human wellbeing globally (Pinillos et al., 2016). Research has indicated that veterinarians were aware of the link between animal abuse and human violence (Benetato et al., 2011; Lockwood \& Arkow, 2016; Robertson, 2010); yet studies in Australia, NZ and the USA reported that they were still reluctant to report cases of animal abuse (Donley et al., 1999; Green \& Gullone, 2005; Williams et al., 2008) due to barriers such as lack of training and lack of helpful resources.
Concern about animal abuse is not just about a clinical focus, but also about the deontological positions in which individuals consider what action to take in relation to the duties, obligations, rights and the welfare of animals (Szucs et al., 2012). Social work has been connected to human animal issues in practice for over 30 years starting with Gerda Bikales (1975) who called for consideration of human-animal relationships in intervention planning. The development of VSW by Dr Elizabeth Strand, as mentioned earlier, has pioneered the intersection between veterinary medicine and social work practice, focusing on the human side of the humananimal bond (HAB) through four key areas: grief and loss of an animal, compassion fatigue in the animal service fields, the link between animal abuse and human violence, and animal-assisted intervention (Holcombe et al., 2016). Because social work aims to be a justice-oriented profession, we also have a duty to consider Indigenous knowledge and interconnectedness with the role of other-than-humans to understand the animal rights movement from a deeper and often spiritually guided authentic attachment to address and strengthen human relations with animals to reduce the prevalence of animal abuse and human violence (Legge \& Robinson, 2017; McGinnis et al., 2019). Based on this evidence, the collaboration between social work and veterinary science was deemed to be an important first step to address the intersection through supporting veterinarian students receiving foundational training so that they can diagnose animal abuse from their veterinarian training but also learn how to deal with animal and human victims of abuse.

\section{Workshop structure and content}

The workshop consisted of three parts. Part one was a lecture-type presentation, which delivered information on (1) an overview of veterinary social work; (2) animal abuse and family violence; (3) ethical dilemmas for professionals to deal with disclosure and reporting; and (4) the Aotearoa New Zealand experience on addressing animal abuse and 
human violence. The second part of the workshop presented four case scenarios for students to work on in groups. The final part offered practical guidance for veterinarians. The following provides a more detailed discussion for each section.

\section{Veterinary social work (VSW)}

As stated earlier, our conception of the workshop was based on VSW through reference to the work of Dr Elizabeth Strand who coined the term in 2002, examining the intersection of veterinary medicine and social work practice (Holcombe et al., 2016; Strand et al., 2012). The main areas of VSW address: grief and pet loss; animal-assisted interactions; the link between human and animal violence; and compassion fatigue management. Although VSW has been around for nearly 20 years, this is still a relatively new field in Aotearoa New Zealand. Some anecdotal evidence of social workers being linked with veterinary clinics to discuss animal welfare and human violence issues exist informally in the field; yet there is limited integration and collaboration at tertiary programme and curriculum development levels. It remains unknown how the topics of animal abuse and family / domestic violence are being taught pro-actively or reactively within veterinary science. Given the targeted audiences were first-year veterinary students, their preliminary views of studying veterinary medicine could be more rooted in clinicalfocused interventions, rather than at the level of internalisation of professional values and adoption of professional behaviours (Armitage-Chan \& May, 2018). Hence, during this part of the workshop, information was introduced to students to connect them with a mutual understanding and acceptance of the HAB between veterinary and social work practices to build a foundational relationship with the students.

\section{Animal abuse and family violence}

This section focused on discussing the link between animal abuse and family violence. A brief review of core literature (both international and from Aotearoa New Zealand) regarding the link between animal abuse and family violence was presented (e.g., Febres et al., 2014; Roguksi, 2012; Signal et al., 2018). Key information was presented regarding family violence in Aotearoa New Zealand regarding: a definition of family violence; prevalence of family violence; child abuse and neglect; legislative and policy responses (Atwool, 2020; Family Violence Death Review Committee, 2017). Information regarding a veterinarian's professional and legal obligations in relation to animal abuse and family violence was presented, drawn from the Veterinary Council of New Zealand's Code of Professional Conduct (2020).

\section{Ethical decisions}

Professionals are often faced with decisions that include an ethical dimension. For veterinarians faced with a situation where animal abuse is evident, they will also need to consider implications for the animal owner and other persons living in the owner's household. The Veterinary Council Working Party (2013) provided guidance for veterinarians in dealing with cases of suspected or actual animal abuse and family violence.

Prior to completing case studies that consider possible links between animal abuse and family violence, the students were introduced to two ethical positions that provide a foundation for ethical decision making. First, duty ethics, that is concerned with gaining an understanding of what is good and right by considering what duties each person has towards other people (e.g., confidentiality). From this position an action is right if it is in accordance with a moral rule or principle (e.g., the right to self-determination, confidentiality). Second, consequentialist ethics, where the rightness or wrongness of an action is based on the consequences that action has for other persons (Hugman, 2008). The focus on this discussion was to give these first-year students some foundational 
knowledge to think about animal welfare and ethics (AWE) (Tzioumis et al., 2018) rather than philosophical debates. Although authors of this viewpoint paper did not have any veterinary training background, our consultation with SG in the Veterinary School, along with research and literature (e.g., Armitage-Chan \& May, 2018), indicated that teamwork through group work and reflection, communication skills and ethical reasoning on ethical or welfare dilemmas, and the consequences for the animal, people and the public were crucial curriculum content in first-year students' pre-clinical year, further forming a strong rationale of our workshop content.

In addition, SG informed us that professional studies teaching in medical and veterinary education has been undergoing major changes to move away teaching students professional behaviours to designing curriculum that supports them to develop professional identity associated with emotional resilience and success in practice to facilitate complexity in professional decision-making. As such, it was important to support veterinary students to resolve professional dilemmas by extending beyond applying "best evidence" in clinical medicine. To help veterinarian students build skills for decision negotiation and implementation such as when dealing with ethical problem solving, resources on the HAB and public health were considered valuable in articulating the immediate (to the client/ person who is the victim of family / domestic violence) and wider (to the public) consequences of the veterinarian's actions. The information-gathering of resources that were important to help veterinarian's decision-making in complex situations was facilitated by us providing and discussing the importance of a professional code of ethics (codes provide guidance that takes account of both the duty and consequentialist perspectives). This aligned well with how Armitage-Chan (2020) conceptualised professional reasoning to help construct one's professional knowledge, skills and judgement, rather than representing personal opinions and worldviews. Two examples of codes were identified in the presentation: The Veterinary Council of New Zealand's (VCNZ's) Code of Professional Conduct (2020), and the Aotearoa New Zealand Association of Social Workers Code of Ethics (2019). Students were asked to consider whether a veterinarian would be morally justified to report suspected cases of abuse to the appropriate authorities. If so, is the professional legally authorised to report the case even when bound by the rule of professional secrecy? (Lachance, 2016). What issues are involved when making decisions that contain an element of concern? What factors should be taken into account?

\section{The Aotearoa New Zealand experiences}

Students were introduced to multiple studies that have been conducted in Aotearoa New Zealand in relation to animal abuse and human violence (Roguksi, 2012), drawing on the Women's Refuge knowledge and experiences, veterinarians' knowledge and attitudes regarding animal abuse and domestic, family or interpersonal violence (Robertson, 2010; Williams et al., 2008) and its implication on veterinary pathology (Lockwood \& Arkow, 2016). The purpose of introducing the previous research formed a process of fact-finding to communicate the complexity of the issue from multiple stakeholders. This was intended to unveil the conflict between the responsibilities that must be balanced by the veterinarians, as legal and professional obligations may not align with societal expectations, the needs of the clients, or evidence described as best practice mainly from a clinical perspective (Grimm et al., 2018). Rather than engaging with the situation of animal abuse and family violence as a private problem, the workshop content intended to help students to start learning how to articulate the reasons and explanations for concerns from professional judgement rather than a subjective or simplistic evaluation. 


\section{Case studies}

The second half of the workshop involved students forming into four to six small groups-each group was assigned a case study to consider. Each case study contained information that potentially linked animal abuse and family violence and each group was given 15 minutes to discuss following questions and then presented their findings and reflections back to the whole class:

- How can you tell there may be suspicious around animal and family / human abuse or neglect?

- What strategies may help you to facilitate the situation?

- What are some of the challenges that you may face in this situation?

- After your discussion, you can nominate a spokesperson to provide feedback to the whole class.

\section{Guidance for veterinarians}

Information produced by the by Veterinary Council Working Party (2013) established the basis of discussion regarding identification of animal abuse and situations where family violence is suspected. Two flow charts derived from its guidance for veterinarians dealing with cases of suspected or actual animal abuse and family violence were shown to students describing which processes could be facilitated when encountering animal abuse and human violence. By providing some practical strategies and guidance, the workshop moved away from bioethical models of veterinary clinical use to focus on the issue of animal abuse or welfare (Mullan \& Main, 2001) to incorporate knowledge in veterinary ethics, the $\mathrm{HAB}$, professional responsibilities, clinical reasoning by joining communication skills, group reflection and review of decision-making and its outcomes.

\section{Gaining students' perspectives}

During the first part of the workshop, we stopped periodically and asked students for their perspectives on their perceptions, knowledge and attitudes on animal abuse and interpersonal violence by using an online polling application, Mentimeter (https://www.mentimeter.com/). We sought low-risk notification from Massey University to collect these data for research purposes. Students were informed that the data collected remained anonymous and their participation to undertake the online polling was voluntary. Table 1 shows pre-workshop data for students' selfperceived responsibility and obligations of a veterinarian in animal welfare and family violence in 2016 and 2017. Results, similar to Williams et al,'s (2008) study conducted in Aotearoa New Zealand, showed that the majority of the veterinary students in both cohorts ( $98 \%$ and $94 \%$ respectively) felt quite strongly that veterinarians should

Table 1. Responsibility and Obligations of Being a Veterinarian in Animal Welfare and Family Violence Based on Responses from Veterinarian Students in 2016 and 2017

\begin{tabular}{|l|c|c|}
\hline $\begin{array}{l}\text { Vets should be legally required to report } \\
\text { suspected animal welfare abuse to the SPCA } \\
\text { and/or police }\end{array}$ & $(N=100)$ & $(N=101)$ \\
\hline $\begin{array}{l}\text { Yes definitely } \\
\text { Yes, to some degree }\end{array}$ & $55(55 \%)$ & $47(47 \%)$ \\
\hline Not really & $43(43 \%)$ & $47(47 \%)$ \\
\hline Not at all & $0(0 \%)$ & $7(7 \%)$ \\
\hline Don't really care & $1(1 \%)$ & $0(0 \%)$ \\
\hline Don't know & $1(1 \%)$ & $0(0 \%)$ \\
\hline $\begin{array}{l}\text { Vets should be taught how to deal with cases } \\
\text { of animal abuse and family violence }\end{array}$ & $0(0 \%)$ & $0(0 \%)$ \\
\hline Yes definitely & $62(62 \%)$ & $70(79 \%)$ \\
\hline Yes, to some degree & $33(33 \%)$ & $17(19 \%)$ \\
\hline Not really & $4(4 \%)$ & $2(2 \%)$ \\
\hline Not at all & $0(0 \%)$ & $0(0 \%)$ \\
\hline Don't really care & $1(1 \%)$ & $0(0 \%)$ \\
\hline Don't know & $0(0 \%)$ & $0(0 \%)$ \\
\hline
\end{tabular}


be legally required to report suspected animal welfare abuse to the SPCA and/ or police. They also felt strongly that veterinarians should be taught how to deal with cases of animal abuse and family violence (95\% and 98\% respectively). In 2018 , we asked veterinary students to rate three statements for their views on animal abuse and human violence (see Table 2). Over $90 \%(4.7 / 5)$ reported agreeing that vets have a moral and a legal responsibility to intervene where they suspect animal abuse while $80 \%(4 / 5)$ agreed that "people who abuse their animals are more likely to abuse their children and/or spouse." This response was particularly interesting and positions veterinarians as the potential key to mitigate family / domestic violence as some pet owners described veterinarians as "the other family doctor" (National Link Coalition, 2019, p.9), indicating this relationship could provide rapport and trust to those who experienced vulnerability.

Table 2. Views on Animal Abuse and Human Violence - Responses from 2018 Veterinarian Students $(N=98)$

\begin{tabular}{|l|c|c|}
\hline Statements & $\begin{array}{c}2018 \\
\text { Mean* (\%) }\end{array}$ & $\begin{array}{c}200 \mathbf{8}^{\wedge} \\
\%\end{array}$ \\
\hline $\begin{array}{l}\text { Vets have a moral and a legal responsibility } \\
\text { to intervene where they suspect animal } \\
\text { abuse }\end{array}$ & $\begin{array}{l}4.7 / 5(94 \%) \\
97 \%\end{array}$ \\
\hline $\begin{array}{l}\text { People who abuse their animals are more } \\
\text { likely to abuse their children and/or spouse }\end{array}$ & $4 / 5(80 \%)$ & $74 \%$ \\
\hline $\begin{array}{l}\text { I feel confident to deal with suspected } \\
\text { association between animal abuse and } \\
\text { family violence }\end{array}$ & $2.4 / 5(48 \%)$ & $13 \%$ \\
\hline
\end{tabular}

*1 = strongly disagree to 5 = strongly agree

$\wedge$ Williams et al. (2008)

Table 3. Average of Workshop Evaluation Between 2016, 2017 and 2018 ( $N=299)$

\begin{tabular}{l|c|}
\hline Statements & $\begin{array}{c}\text { Mean }^{*} \\
\text { (over three-year) }\end{array}$ \\
\hline The workshop was interesting & $3.5 / 5$ \\
\hline I learnt new things & $3.5 / 5$ \\
\hline The content was relevant & $3.8 / 5$ \\
\hline It will help my vet training and professional development & $3.8 / 5$ \\
\hline
\end{tabular}

*1 = strongly disagree to 5 = strongly agree
However, only $48 \%$ reported to "feel confident to deal with suspected association between animal abuse and family violence." These results were also similar to Williams et al.'s (2008). Students' evaluations of the workshop over the three years (2016, 2017 and 2018) were also collected. Table 3 shows on average, $70 \%$ felt "the workshop was interesting" and "I learnt new things." Over 75\% felt "the content was relevant" and "it will help my vet training and professional development." In addition, veterinary students were also asked to type the barriers that may prevent veterinarians from exercising these professional and legal obligations through the online polling application. Answers were collated and streamed into root words through a Wordle application online (http: / / www.wordle.net/) (see Figure 1). They frequently reported "fear of losing/offending clients"; lack of "concrete proofs, evidence"; already formed "relationship with clients"; they may get it "wrong"; and "absence of support" as the main barriers, consistent with Robertson's (2010) reporting.

\section{Practice reflection}

The workshop has been a successful interdisciplinary partnership between the two schools. While currently published evidence of implementation and success of veterinary student education regarding the link between animal abuse and family violence is limited (Newland et al., 2019), the collaboration can be seen as addressing the educational gaps of veterinary student education about the link. Due to the limited published literature regarding the design, implementation and success of veterinary training focusing on the link between animal abuse and family violence and its relevance in the clinical context, contextualisation has been the main pedagogy that enhances meaningful learning in the area concerned (Litchfield et al., 2010). The two-hour duration for the workshop format sought to provide a balance of teaching approaches, including: direct instruction via Power 
Point, synchronous online polling, use of questioning and reflection, and student scenario-based learning. The development of the workshop showed a similar pattern to how Armitage-Chan (2020) has developed a comprehensive professional reasoning framework to support professional identity formation among veterinarian students. The relevance of the topic has been supported by the feedback received from veterinary students and the college, and this workshop continued to be part of the veterinary professional skills programme in 2019 and 2020. However, the location of the workshop within the five-year veterinary degree programme is subject to review, and it may be better placed later, when the students' sense of professional identify has consolidated and they are closer to commencing practice.

Veterinarians have been identified as potential frontline professionals to recognise and intervene in animal abuse and family violence (Newland et al., 2019; Randour et al., 2019) but they will need to have greater access to resources and continuing education to build confidence in dealing with animal abuse and its association with family violence. Recent research has advocated for ongoing cooperation, coordination, cross-training and consultation between human service and animal service professionals (Randour et al., 2019). Interprofessional collaborations are bolstered through the ability of social workers and academics to analyse, develop and utilise their collaborative skills to empower interprofessional teams. Social work's knowledge and expertise in detecting and dealing with interpersonal violence can work collaboratively with veterinary professionals to include the HAB through an interdisciplinary approach to practice (Arkow, 2020). Other areas of VSW such as grief and pet loss; animal-assisted interactions; and compassion fatigue management present further opportunities for interdisciplinary collaboration. Social work could contribute to veterinary student training regarding interpersonal

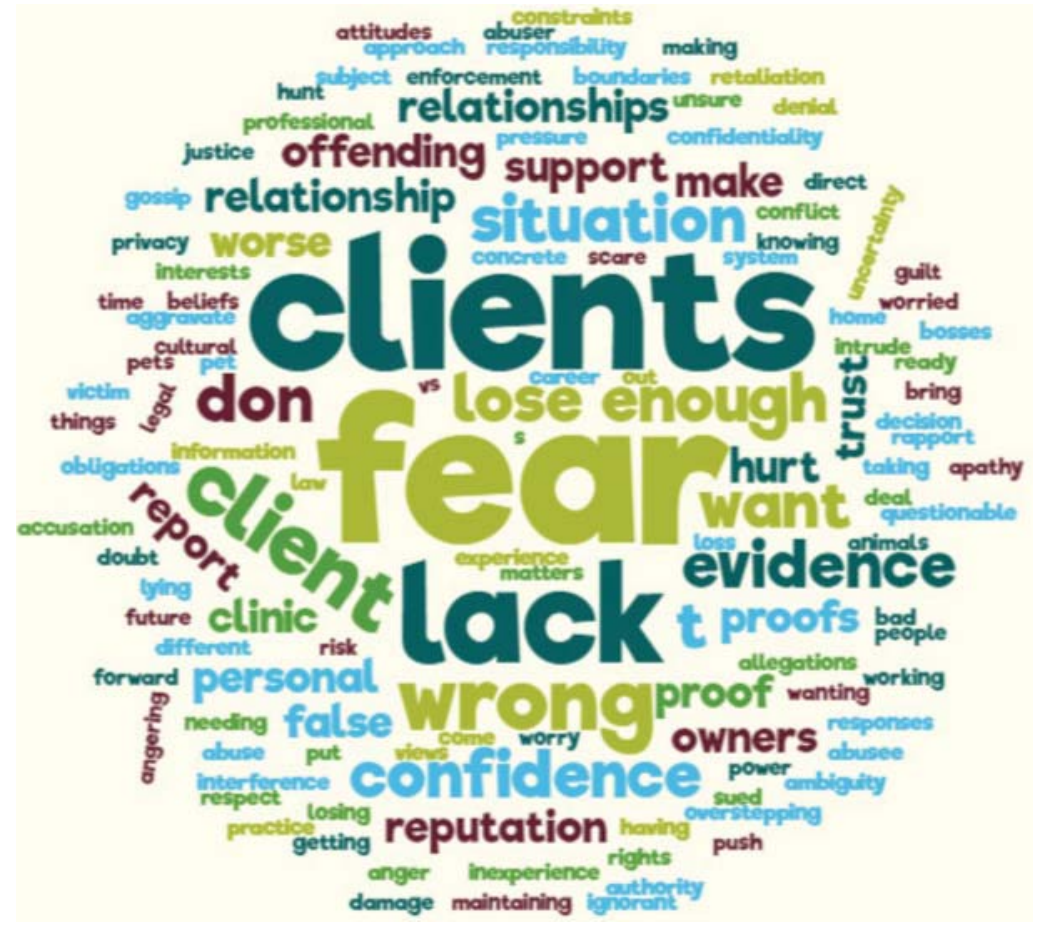

Figure 1. Word Cloud Representation of Words Reported by Veterinarian Students $(N=106)$ Describing Barriers Preventing Veterinarians Reporting Animal Abuse and/or Family Violence.

communication and the development of professional identity.

\section{Acknowledgement}

The authors would like to thank Dr. Stuart Gordon for his ongoing collaboration and support to work with veterinary students.

\section{References}

Aotearoa New Zealand Association of Social Workers. (2019). Code of ethics 2019. https://anzasw.nz/wpcontent/uploads/ANZASW-Code-of-Ethics-Final-1Aug-2019.pdf

Arkow, P. (2015a). A link across the lifespan: Animal abuse as a marker for traumatic experiences in child abuse, domestic violence and elder abuse. Academy on Violence and Abuse. https://avahealthorg.presencehost. net/file_download/inline/b64aff80-5461-4d9b-9cdccf9b47f30174

Arkow, P. (2015b). Recognizing and responding to cases of suspected animal cruelty, abuse, and neglect: What the veterinarian needs to know. Veterinary Medicine: Research \& Report, 6, 349-359.

Arkow, P. (2020). Human-animal relationships and social work: Opportunities beyond the veterinary environment. Child \& Adolescent Social Work Journal. https://doi. org/10.1007/s10560-020-00697-x 
Armitage-Chan, E. (2020). Best practice in supporting professional identity formation: Use of a professiona reasoning framework. Journal of Veterinary Medical Education, 47(2), 125-136.

Armitage-Chan, E., \& May, S. A. (2018). Developing a professional studies curriculum to support veterinary professional identity formation. Journal of Veterinary Medical Education, 45(4), 489-501.

Ascione, F., Weber, C. V., \& Wood, D. S. (1997). The abuse of animals and domestic violence: A national survey of shelters for women who are battered. Society and Animals, 5(3), 205-218.

Atwool, N. (2020). Care and protection/family violence: Aotearoa New Zealand. Children Australia, 45, 5-7.

Benetato, M.A., Reisman, R., \& McCobb, E. (2011). The veterinarian's role in animal cruelty cases. Journal of American Veterinary Medical Association, 238, 31-34.

Bikales, G. (1975). The dog as "significant other". Social Work, 20(2), 150-152

Bright, M.A., Huq, M.S., Spencer, T., Applebaum, J.W., \& Hardt, N. (2018). Animal cruelty as an indicator of family trauma: Using adverse childhood experiences to look beyond child abuse and domestic violence. Child Abuse \& Neglect, 76, 289-296.

Courtenay, M., Wilkes, M., Conrad, P. A., La Ragione, R., \& Reeves, S. (2014). One Health: The importance of education and the impact of interprofessional interventions. The Veterinary Journal, 201, 241-242.

Donley, L., Patronek, G. J., \& Luke, C. (1999). Animal abuse in Massachusetts: A summary of case reports at the MSPCA and attitudes of Massachusetts veterinarians. Journal of Applied Animal Welfare Science, 2, 59-73.

Family Violence Death Review Committee. (2017). Family Violence Death Review Committee's fifth report data Media summary. Family Violence Death Review Committee.

Faver, C., \& Strand (2003). Domestic violence and animal cruelty. Journal of Social Work Education, 39(2), 237-253.

Febres, J., Brasfield, H., Shorey, R. C., Elmquist, J., Ninnemann, A., Schonbrun, Y. C., Temple, J. R. Recupero, P. R., \& Stuart, G. L. (2014). Adulthood animal abuse among men arrested for domestic violence. Violence Against Women, 20(9), 1059-1077.

Green, P. C., \& Gullone, E. (2005). Knowledge and attitude of Australian veterinarians to animal abuse and human interpersonal violence. Australian Veterinary Journal, 83(10), 619-625.

Grimm, H., Bergadano, A., Musk, G. C., Otto, K., Taylor, P., \& Duncan, J. C. (2018). Drawing the line in clinical treatment of companion animals: Recommendations from an ethics working party. The Veterinary Record, 182(23), 664-671.

Haden, S. C., McDonald, S. E., Booth, L. J., Ascione, F. R., \& Blakelock, H. (2018). An exploratory study of domestic violence: Perpetrators' reports of violence against animals. Anthrozoös, 31(3), 337-352.

Holcombe, T. M., Strand, E. B., Nugent, W. R. \& Ng, Z. Y. (2016). Veterinary social work: Practice within veterinary settings. Journal of Human Behavior in the Social Environmen., doi:10.1080/10911359.2015.1059170
Hugman, R. (2008). An ethical perspective on social work. In M. Davies (3rd ed.). The Blackwell companion to social work (pp. 442-448). Blackwell Publishing.

Jordan, T., \& Lem, M. (2014). One Health, One Welfare: Education in practice. Veterinary students' experiences with community veterinary outreach. Canadian Veterinary Journal, 55(12), 1203-1206.

Lachance, M. (2016). Breaking the silence: The veterinarian's duty to report. Animal Sentience, 6(1).

Legge, M. M., \& Robinson, M. (2017). Animals in indigenous spiritualities: Implications for critical social work. Journal of Indigenous Social Development, 6(1), 1-20.

Litchfield, A., Frawley, J., \& Nettleton, S. (2010). Contextualising and integrating into the curriculum the learning and teaching of work-ready professional graduate attributes. Higher Education Research \& Development, 29, 519-534.

Lockwood, R., \& Arkow, P. (2016). Animal abuse and interpersonal violence: The cruelty connection and its implications for veterinary pathology. Veterinary Pathology, 53, 910-918.

Long, D., Long, J., \& Kulkarni, S. (2007). Interpersona violence and animals: Mandated cross-sector reporting. Journal of Sociology \& Social Welfare, XXXIV(3), 147-163.

McGinnis, A., Tesarek Kincaid, A., Barrett, M. J., Ham, C., \& Community Elders Research Advisory Group. (2019). Strengthening animal-human relationships as a doorway to indigenous holistic wellness. Ecopsychology, 11(3), 162-173.

Mullan, S., \& Main D. (2001). Principles of ethical decisionmaking in veterinary practice. In Practice, 23(7), 394-401.

National Link Coalition. (2019). The connection between animal cruelty and societal violence and vulnerability. LINK-Letter, 12(12), 9-10.

Newberry, M. (2017). Pets in danger: Exploring the link between domestic violence and animal abuse. Aggression \& Violent Behavior, 34, 273-281.

Newland, X., Boller, M., \& Boller, E. (2019). Considering the relationship between domestic violence and pet abuse and its significance in the veterinary clinical and educational contexts. New Zealand Veterinary Journal, 67(2), 55-65.

Pinillos, R. G., Appleby, M. C., Manteca, X., Scott-Park, F., Smith, C., \& Velarde, A. (2016). One welfare - A platform for improving human and animal welfare. Veterinary Record, 179, 412-413.

Randour, M. L., Smith-Blackmore, M., Blaney, N., DeSousa, D., \& Guyony, A. (2019). Animal abuse as a type of trauma: Lessons for human and animal service professionals. Trauma, Violence \& Abuse. doi:10.1177/1524838019843197

Robertson, I. (2010). Legally protecting and compelling veterinarians in issues of animal abuse and domestic violence. New Zealand Veterinary Journal, 58(3), 114-120.

Roguksi, M. (2012). Pets as pawns: The co-existence of animal cruelty and family violence. http:// nationallinkcoalition.org/wp-content/uploads/2013/01/ DV-PetsAsPawnsNZ.pdf

Signal, T., Taylor, N., Burke, K. J., \& Brownlow, L. (2018). Double jeopardy: Insurance, animal harm, and domestic violence. Violence Against Women, 24(6), 718-726. 
Strand, E. B., Poe, B. A., Lyall, S., Yorke, J., Nimer, J., Allen, E., Brown, G., \& Nolen-Pratt, T. (2012). Veterinary social work practice. In C. Dulmus \& K. Sowers (Eds.). Social work: Fields of practice (pp. 245-271). John Wiley \& Sons.

Szucs, E., Geers, R., Jezierski, T., Sossidou, E. N., \& Broom, D. M. (2012). Animal welfare in different human cultures, traditions and religious faiths. Asian-Australian Journal of Animal Sciences, 25(11), 1499-1506.

Tzioumis, V., Freire, R., Hood, J., Johnson, A. J., Lloyd, J., Phillips, C. J. C., \& McGreevy, P. D. (2018). Educators' perspectives on animal welfare and ethics in the Australian and New Zealand veterinary curricula. Journal of Veterinary Medical Education, 45(4), 448-463.

Veterinary Council of New Zealand. (2020). Code of professional conduct for veterinarians. https://www. vetcouncil.org.nz/Web/Code_of_Professional_Conduct/ Code_Of_Conduct.aspx

Veterinary Council Working Party. (2013). Guidance for veterinarians: Dealing with cases of suspected or actual animal abuse and family violence. https://www. vetcouncil.org.nz/Web/Publications/Type/Guidelines and_Standards.aspx

Volant, A. M., Johnson, J. A., Gullone, E. \& Coleman, J. (2008). The relationship between domestic violence and animal abuse: An Australian study. Journal of Interpersonal Violence, 23(9), 1277-1295.

Williams, V., Dale, A., Clarke, N. \& Garrett, N. (2008). Anima abuse and family violence: Survey on the recognition of animal abuse by veterinarians in New Zealand and their understanding of the correlation between animal abuse and human violence. New Zealand Veterinary Journal, 56(1), 21-28. 